\title{
PENERAPAN TOLOK UKUR MAC DARI GREENSHIP NEIGHBORHOOD VERSI 1.0 DAN EVALUASI SUBJEKTIF PADA KAWASAN KEBUN RAYA INDROKILO DI BOYOLALI.
}

\author{
Naufal Kholid \\ Program Studi Arsitektur Fakultas Teknik \\ Universitas Muhammadiyah Surakarta \\ e-mail: naufalkholid9719@gmail.com
}

\section{Nur Rahmawati Syamsiyah}

Program Studi Arsitektur Fakultas Teknik Universitas Muhammadiyah Surakarta e-mail: nur_rahmawati@ums.ac.id

\begin{abstract}
ABSTRAK
Kebun Raya Indrokilo (KRI) merupakan kawasan cagar alam yang dibangun sebagai sarana edukasi dan konservasi tumbuhan hutan hujan dataran rendah dan sebagai bentuk upaya menjaga keanekaragaman hayati dari degradasi habitat. Untuk itu kawasan ini menarik untuk diteliti bagaimana penerapan arsitektur hijau pada kawasan serta bagaimana opini pengunjung mengenai sarana yang ada. Penelitian ini ditujukan untuk menilai penerapan tolok ukur movement and connectivity (MAC) dan mengetahui evaluasi subjektif dari pengunjung. Metode yang digunakan adalah deskriptif kualitatif berupa penjelasan dari penilaian parameter MAC, dan metode kuantitatif dalam memberikan penilaian dan prosentase evaluasi subjektif. Data hasil tolok ukur MAC dikomparasikan dengan hasil wawancara dengan jumlah sample 20 orang pengunjung Kebun Raya dengan intensitas kunjungan yang bervariasi. Hasil yang diperoleh dari kawasan ini adalah Kebun Raya Indrokilo memenuhi 17 nilai dari 26 nilai maksimal pada kategori MAC dan persentase kepuasan pengunjung sebesar $45 \%$. Adanya upaya penerapan arsitektur hijau pada kawasan Kebun Raya Indrokilo oleh pengelola, dapat dilihat dari penilaian MAC dari greenship yang diterapkan oleh KRI mencapai $13 \%$ dari $21 \%$ persentase maksimal pada kategori tersebut tetapi perlu adanya sinergi antara penerapan greenship dengan upaya edukasinya kepada masyarakat.
\end{abstract}

KATA KUNCI : arsitektur, arsitektur hijau, kebun raya, kebun botani

\section{PENDAHULUAN}

Indonesia dikenal sebagai Negara dengan kekayaan hayati yang berlimpah, lebih dari $10 \%$ jenis tumbuhan diseluruh dunia atau setidaknya 25.000 jenis tumbuhan menjadi kekayaan flora Indonesia. Namun, keberlangsungan hidup tumbuhan asli di Indonesia mulai terancam karena terjadinya perubahan iklim sebagai akibat kenaikan suhu yang terjadi belakangan ini. Kenaikan suhu tersebut terjadi sejak revolusi industri karena adanya peningkatan jumlah emisi gas efek rumah kaca. Hal ini menyebabkan terjadinya fenomena alam seperti kebakaran hutan, banjir dan sebagainya. Kondisi ini diperparah dengan kerusakan yang ditimbulkan oleh manusia sendiri yang sebagian berdampak bagi flora yang ada. Semakin maraknya pertumbuhan penduduk serta pemanfaatan sumber daya alam yang ada tanpa memperhatikan pembaharuannya. Ditambah lagi permintaan akan kebutuhan ruang yang semakin meningkat, baik untuk kebutuhan rumah tinggal maupun fasilitas lainnya mengakibatkan open space semakin menipis.

Perlu dilakukan evaluasi dan usaha untuk menanggulangi degradasi alam. Pembangunan yang berkelanjutan diperlukan untuk mengatasi masalah ini, dengan tidak mengurangi kemampuan generasi mendatang dalam memenuhi kebutuhannya. Target ini dapat terpenuhi salah satunya dengan penerapan Greenship Architecture dengan menggunakan perangkat greenship neighborhood versi 1.0 yang dikeluarkan oleh $\mathrm{GBCl}$.

Kebun Raya Indrokilo merupakan salah satu usaha dari pemerintah Kabupaten Boyolali yang dicanangkan oleh Bupati Boyolali sebagai salah satu upaya dalam mengembangkan dan menyelamatkan lingkungan. Kebun Raya ini merupakan tempat pemeliharaan, edukasi, rekreasi dan sebagai tempat penyelamatan tumbuh-tumbuhan yang mulai langka karena degradasi habitat. Degradasi habitat adalah penurunan kualitas tempat tinggal makhluk hidup tertentu yang dipicu oleh aktivitas manusia maupun alam yang berdampak kepada habitat tersebut tetapi pada manusia karena kawasan yang terdegradasi menjadi hilang karena desertifikasi tanah, erosi, dan penipisan nutrisi pada tanah. Kondisi Kebun Raya Indrokilo yang masih baru, memungkinkan akan terus berkembang, sehingga agar tidak salah arah maka perlu untuk diukur, sehingga perkembangannya 
menjadi lebih baik. Selain itu perlu dilakukan evaluasi untuk mengetahui sejauh mana kepuasan pengunjung mengenai fasilitas yang tersedia pada Kebun Raya ini sehingga kedepannya dapat dijadikan bahan untuk berbenah. Tujuan dari penelitian ini adalah :

1. Mengetahui tolok ukur yang sudah diterapkan pada kawasan Kebun Raya Indrokilo mengenai Movement and Connectivity (MAC).

2. Mengetahui pendapat subjektif dari pengunjung tentang fasilitas yang ada.

3. Mengetahui aspek pencapaian dan konektivitas yang bisa dikembangkan.

\section{TINJAUAN PUSTAKA}

Kebun Raya merupakan suatu kawasan yang mengkoleksi berbagai jenis tumbuhan. Tumbuhan yang dikoleksi kebun raya memiliki dasar ilmiah dan informasi ilmiah mengenai koleksinya yang terdokumentasi dengan baik. Fungsi dari Kebun Raya adalah sebagai tempat konservasi ex-situ, tempat penelitian, tempat pendidikan lingkungan, dan tempat wisata (LIPI, 2007). Peraturan Pemerintah No. 93 tahun 2011 menyebutkan bahwa Kebun Raya adalah kawasan konservasi tumbuhan secara ex situ yang memiliki koleksi tumbuhan terdokumentasi dan ditata berdasarkan pola klasifikasi taksonomi, bioregion, tematik, atau kombinasi dari pola-pola tersebut untuk tujuan kegiatan konservasi, penelitian, pendidikan, wisata dan jasa lingkungan.

$\mathrm{GBCl}$ atau Green Building Council Indonesia adalah sebuah Lembaga mandiri (non pemerintah) yang merupakan bagian dari World Green Building Council yang pusatnya berada di Toronto, Canada. Didirikan sejak tahun 2009 oleh para profesional di sektor perancangan dan konstruksi yang memiliki fokus pada bangunan hijau atau bangunan yang menerapkan konsep green architecture. Sistem rating atau perangkat tolok ukur adalah sebuah pedoman yang berisi butir-butir dari aspek penilaian yang disebut rating. Setiap ratingnya memiliki nilai atau credit point. Sistem rating yang dikeluarkan oleh $\mathrm{GBCl}$ salah satunya adalah greenship neighborhood versi 0.1 untuk menilai sebuah kawasan. Jenis Sertifikasi Greenship Kawasan yang terdiri dari :

\section{Plan}

Pada tahap ini, tim proyek mendapat kesempatan untuk mendapatkan penghargaan untuk proyek pada tahap finalisasi desain dan perencanaan berdasarkan perangkat penilaian greenship. Jenis sertifikasi ini untuk kawasan yang masih dalam tahap perencanaan.

\section{Built Project}

Untuk proyek yang telah terbangun dan/atau telah beroperasi. Proyek dinilai secara menyeluruh baik dari aspek desain, konstruksi maupun operasional; untuk menentukan kinerja kawasan secara menyeluruh.

\section{METODOLOGI PENELITIAN}

Penelitian ini merupakan evaluasi objektif dengan menggunakan kategori MAC dari perangkat penilaian greenship neighborhood versi 1.0 dan evaluasi subjektif dari masyarakat yang dalam konteks penelitian ini merupakan pegunjung dari Kawasan Kebun Raya Indrokilo. Kategori Movement and Connestivity (MAC) digunakan untuk mengetahui bagaimana penerapan mengenai pergerakan dan konektivitas pada sarana penunjang yang ada di kawasan. Sebelumnya objek harus sudah memenuhi persyaratan untuk tolok ukur MAC yaitu :

1. Terdapat studi tentang aksesibilitas

2. Penyediaan jalur untuk pejalan kaki

3. Kawasan terkoneksi dengan jaringan transportasi umum dan kawasan menyediakan ruang interkoneksi yang memadai.

Setelah prasyarat terpenuhi, langkah selanjutnya adalah menguraikan kondisi pada objek penelitian yang kemudian diolah sesuai pada tabel MAC. Pemberian nilai menyesuaikan data lapangan dengan tabel, tolok ukur yang terpenuhi maka mendapat nilai sesuai dengan nilai yang tertera pada tabel, sedangkan tolok ukur yang tidak terpenuhi maka mendapat nilai 0 . Kemudian dilakukan wawancara kepada 20 orang pengunjung dengan rentang usia 18-39 tahun untuk mendapatkan data mengenai pendapat pengunjung tentang akses dan fasilitas penunjang yang ada, diantaranya: pencapaian pada kawasan, parker, kemudahan memuhi kebutuhan fisik, kemudahan dalam fasilitas kebersihan, kepuasan dengan fasilitas yang ada.

\section{HASIL PENELITIAN DAN PEMBAHASAN}

Kebun Raya Indrokilo merupakan Kebun Raya Daerah yang dikelola oleh Dinas Lingkungan Hidup Kabupaten Boyolali. Pembangunan Kebun Raya ini diinisiasi oleh Bupati Boyolali pada tahun 2015 sebagai kawasan edukasi dan konservasi tumbuhan hutan hujan dataran rendah. Hutan hujan dataran rendah merupakan jenis hutan tropis yang letaknya berada pada ketinggian anatara 5 sampai 1000 Mdpl. Kekayaan vegetasi dan tingkat kehidupan relatif subur merupakan ciri khas hutan dataran rendah. (https://rimbakita.com/hutan-dataran-rendah/)

\section{Penilaian Pergerakan dan Konektivitas \\ MAC 1 (Strategi Desain Pejalan Kaki)}

Desain jalur pejalan kaki terkait dengan fasilitas yang tersedia sudah memenuhi dengan standar yang dikeluarkan oleh SE menteri PUPR No. 02/SE/M/2018 seperti fasilitas peneduh, pengaman dan fasilitas 
penyeberangan. Jalur pelajalan kaki terkoneksi dengan seluruh atraksi dan fasilitas yang disediakan oleh KRI, seperti terlihat pada Masterplan di Gambar 1 dan 2.

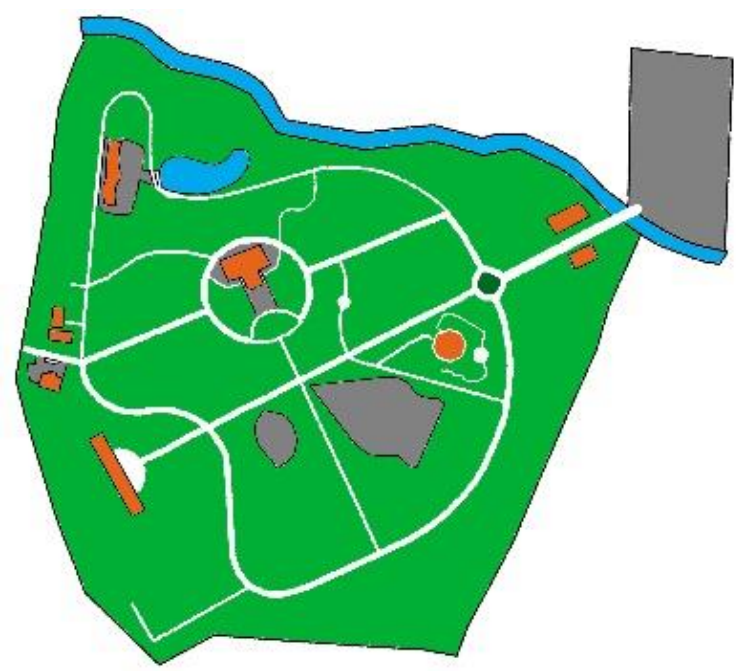

Gambar 1. Masterplan

(Sumber: Analisa Penulis,2019)

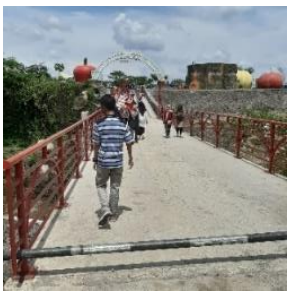

(a)

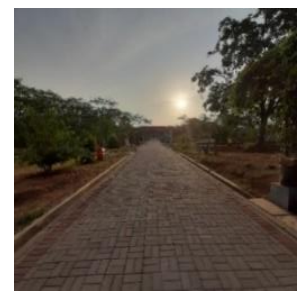

(b)
Gambar 2 Fasilitas Pejalan kaki: (a) Jembatan, (b) Pedestrian.

(Sumber: Dokumentasi Penulis,2019)

\section{MAC 2 (Transportasi Umum)}

Kebun Raya Indrokilo belum memiliki halte atau shelter untuk transportasi umum. Berdasarkan PERDA Kabupaten Boyolali No. 9 Tahun 2011 Kelurahaan Kemiri dilalui oleh angkutan penumpang AKDP (Antar Kota Dalam Provinsi). Jalan yang dilalui oleh trayek tersebut adalah Indrokilo yang berjarak $521 \mathrm{~m}$ dari area terluar kawasan Kebun Raya dimana standar pada greenship jarak maksimal adalah 400 m dari area terluar.

\section{MAC 3 (Utilitas dan Fasilitas Umum)}

Kebun Raya Indrokilo sudah memiliki beberapa prasarana dasar seperti jalan, tempat parkir, penyediaan air bersih, plang/ papan informasi, pos keamanan. Dan sudah dilengkapi dengan beberapa sarana pokok seperti sarana edukasi melalui pembibitan dan koleksi, sarana penunjang seperti playground, TIC, air terjun, plaza dan gedung pengelola, serta sarana pelengkap berupa penyewaan sepeda (lihat Gambar 3).

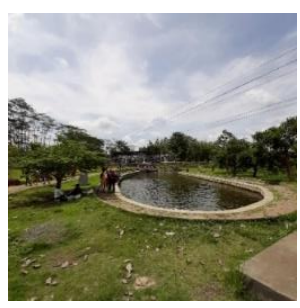

(a)

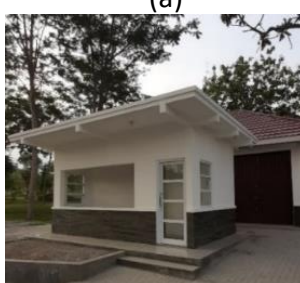

(c)

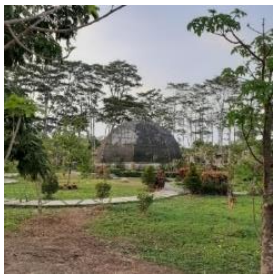

(e)

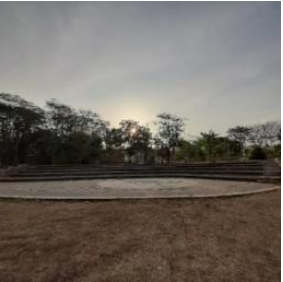

(g)

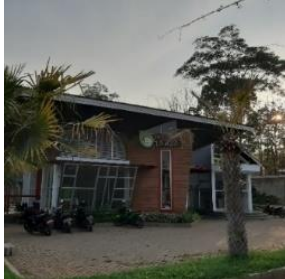

(i)

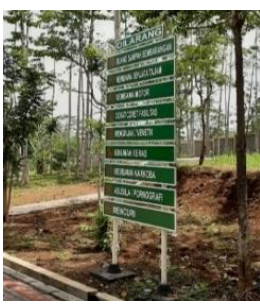

(b)

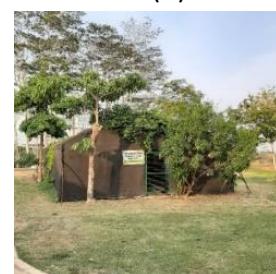

(d)

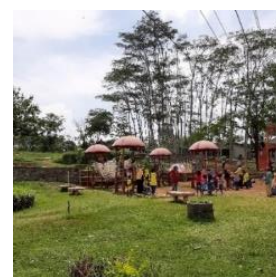

(f)

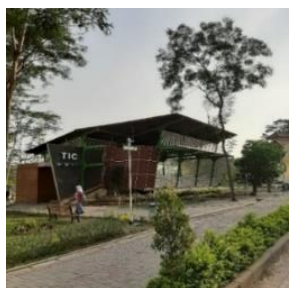

(h)

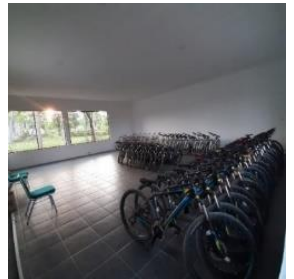

(j)
Gambar 3 (a) Embung Segara Alit, (b) Plang Himbauan, (c) Pos Keamanan, (d) Area Pembibitan, (e) Taman Tematik, (f)

Playground, (g) Plaza, (h) TIC, (i) Gedung pengelola, (j) penyewaan sepeda.

(Sumber: Dokumentasi Penulis,2019)

\section{MAC 4 (Aksesibilitas Universal)}

Ruang publik terdapat di tengah kawasan dengan jalur pejalan kaki yang lebar, sehingga memudahkan pengunjung menuju ruang publik kawasan. Sudah terdapat sitting group sebagai area istirahat bagi pengunjung, namun belum lengkap, dimana belum menyediakan tempat parkir untuk kursi roda dan toilet khusus bagi pengguna kursi roda.

\section{MAC 5 (Jaringan dan Tempat Penyimpanan Sepeda)}

Kawasan Kebun Raya Indrokilo diperuntukkan bagi pejalan kaki dan pengguna sepeda, akan tetapi belum menyediakan tempat parkir khusus sepeda di dalam 
kawasan, sehingga para pengguna sepeda untuk sementara memanfaatkan bahu jalan sebagai tempat parkir sepeda.

\section{MAC 6 (Parkir Bersama)}

Fasilitas parkir kendaraan bermotor pada kawasan Kebun Raya Indrokilo bersifat publik, dimana pemilik kendaraan bermotor dapat parkir di tempat yang sudah disediakan. Penggunaan area parkir pada kawasan dapat dilihat dari perhitungan berikut :

Luas Area Parkir $=0,5$ ha

Luas Kawasan $=8,9$ ha

$$
\begin{aligned}
& \frac{8,9}{100} x \frac{0,5}{x}=(8,9, x) x(0,5.100) \\
& \left.X=\frac{50}{8,9}=5,6 \% \text { (Kurang dari } 10 \%\right)
\end{aligned}
$$

Penggunaan area parkir kawasan kurang dari $10 \%$ dari ketersediaan area parkir. Tabel 1 memperlihatkan hasil penilaian terhadap pergerakan dan konektivitas.

Tabel 1 Penilaian MAC

\begin{tabular}{lcc}
\hline \multicolumn{1}{c}{ Kriteria } & Standar & Nilai \\
\hline \hline $\begin{array}{l}\text { MAC P } \\
\text { Analisa Pergerakan } \\
\text { Orang Dan Barang }\end{array}$ & $\mathrm{P}$ & $\begin{array}{c}\text { Memenuhi } \\
\text { Syarat }\end{array}$ \\
\hline \hline $\begin{array}{l}\text { MAC 1 } \\
\text { Strategi Desain Jalur } \\
\text { Pejalan Kaki. }\end{array}$ & 10 & 10 \\
\hline \hline $\begin{array}{l}\text { MAC 2 } \\
\text { Transportasi Umum }\end{array}$ & 6 & 0 \\
\hline \hline $\begin{array}{l}\text { MAC 3 } \\
\text { Utilitas dan Fasilitas } \\
\text { Umum }\end{array}$ & 2 & 1 \\
\hline \hline $\begin{array}{l}\text { MAC 4 } \\
\text { Aksesibilitas Universal }\end{array}$ & 3 & 2 \\
\hline \hline $\begin{array}{l}\text { MAC 5 } \\
\text { Jaringan dan Tempat } \\
\text { Penyimpanan Sepeda }\end{array}$ & 3 & 2 \\
\hline \hline $\begin{array}{l}\text { MAC 6 } \\
\text { Parkir Bersama }\end{array}$ & 2 & $\mathbf{2}$ \\
\hline \hline Nilai Total & $\mathbf{2 6}$ & $\mathbf{1 7}$ \\
\hline
\end{tabular}

Berikut merupakan perhitungan bobot penilaian dari penelitian :

Total Nilai maksimal (pedoman) : 124

Total Bobot maksimal(pedoman) $\quad: 100 \%$

Total Nilai maksimal MAC $\quad: 26$

Total Bobot maksimal MAC $\quad: 21 \%$

$$
\text { Persetase } M A C=\frac{17}{124} \times 100 \%=13 \%
$$

Penilaian MAC ini sudah termasuk menengah-sedang, karena total dari nilai MAC yang diperoleh melalui penelitian ini yaitu nilai 17 poin dari 26 poin dengan bobot $13 \%$ dari $21 \%$.

\section{Evaluasi Subjektif}

Evaluasi Subjektif diperlukan untuk memberikan penilaian kepuasan pengunjung terhadap fasilitas yang tersedia di kawasan ini. Gambar 4 adalah hasil penilaian subjektif.

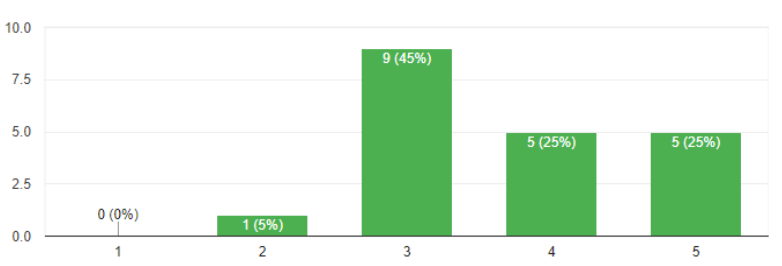

Gambar 4. Kepuasan Pengunjung

(Sumber: Analisa Penulis,2019)

Hasil evaluasi subjektif pada pengunjung adalah sebagai berikut:

1. Pengunjung menilai kemudahan akses menuju kawasan disebabkan terdapat penunjuk jalan pada jalan utama, adanya gapura juga menjadi tanda menuju kawasan, jalan yang luas dan rata menunjukkan kemudahan akses tersebut.

2. Sebagian besar narasumber menganggap mudah untuk parkir pada kawasan karena area yang luas serta dekat dengan pintu masuk.

3. Informasi pada kawasan sangat mudah didapat karena terdapat papan informasi mengenai denah kawasan, papan himbauan, terdapat keterangan pada taman tematik serta nama pada setiap tumbuhan yang ada pada KRI.

4. Tempat duduk yang disediakan di kawasan menurut penilaian pengunjung sangat baik karena kawasan menyediakan sitting group pada beberapa titik, serta adanya tempat duduk di sisi jalan. Akan tetapi beberapa pengunjung menilai kurang, karena tempat duduk berada di spot yang panas dan belum ada peneduh.

5. Kemudahan mencari tempat sampah juga dinilai mudah oleh pengunjung karena tersebar di beberapa titik. Namun, karena pengunjung ramai hanya di titik tertentu saja, sehingga tempat sampah yang disediakan terkadang tidak dapat menampung sampah yang banyak.

6. Penilaian pengunjung terhadap toilet yang disediakan dalam kategori cukup namun cenderung kurang, karena kondisi toilet yang terbatas dan terletak sedikit jauh dari titik ramai pada kawasan sehingga sering menimbulkan antrian yang membuat pengunjung kurang nyaman. 
Dari dua metode yang sudah dilakukan, perlu adanya crosscheck pada hasil tersebut. Adanya upaya penerapan arsitektur hijau pada kawasan Kebun Raya Indrokilo oleh pengelola, dapat dilihat dari penilaian MAC dari greenship yang diterapkan oleh KRI mencapai $13 \%$ dari $21 \%$ persentase maksimal pada kategori tersebut. Pengelola berusaha menghadirkan fasilitas rekreasi alam dengan spot-spot kekinian untuk menjadi daya tarik bagi kaum milenial untuk belajar tentang alam.

Sedangkan realita yang terjadi pada objek, hanya sebagian pengunjung yang memanfaatkan fasilitas yang disediakan, sesuai dengan upaya dari pengelola yang telah dijelaskan di atas. Sedangkan sebagian lainnya datang menikmati rekreasi alam dengan cara yang tradisional seperti memilih untuk duduk di rumput dan menggelar tikar agar dapat makan bersama daripada duduk-duduk di sitting group yang disediakan.

\section{KESIMPULAN}

Hasil penilaian menggunakan tolok ukur MAC pada Kawasan Kebun Raya Indrokilo telah memenuhi 13\% dari $21 \%$ bobot maksimal MAC pada Perangkat Greenship Neighborhood versi 1.0 atau masuk dalam kategori menengah tinggi. Desain jalur pejalan kaki menjadi kategori yang paling banyak mendapatkan nilai dan perlu adanya pengembangan pada kategori transportasi umum.

Luaran tersebut berbanding lurus dengan evaluasi dari pengunjung yang merasakan kemudahan dalam akses menuju kawasan, kenyamanan pada jalur pejalan kaki, serta kenyamanan dengan tempat istirahat berupa sitting group yang disediakan.

Kenyamanan dan kemudahan pada aksesibilitas dan pergerakan tidak begitu berpengaruh pada tingkat kepuasan masyarakat terhadap fasilitas yang ada pada kawasan Kebun Raya Indrokilo. Hal tersebut terbukti pada grafik dari evaluasi subjektif bahwa $45 \%$ pengunjung masuk dalam kategori cukup puas dan hanya $25 \%$ yang sudah merasa sangat puas. Hasil ini menunjukkan simpulan bahwa upaya penerapan green architecture selain menjadi praktik dari para akademisi serta pengelola suatu kawasan akan tetapi juga perlu adanya edukasi mengenai hal tersebut kepada masyarakat umum agar tercapainya kesinambungan dalam upaya penyelamatan lingkungan dengan praktik green architecture.

\section{DAFTAR PUSTAKA}

Ali, B. S. (2016). Strategi pengembangan fasilitas guna meningkatkan daya tarik minat wisatawan. Strategi pengembangan fasilitas guna meningkatkan daya tarik minat wisatawan, 930.

GBCl. (2019). Green Building Council Indonesia. Retrieved from Green Building Council Indonesia: https://gbcindonesia.org/ [Diakses pada tanggal 12 November 2019]

LIPI. (2007, September 24). Kebun Botani : Upaya Melestarikan Kekayaan Hayati. Retrieved from Lembaga Ilmu Pengetahuan Indonesia: Kebun Botani : Upaya Melestarikan Kekayaan Hayati

LIPI. (2019). Kebun Raya Indrokilo Boyolali. Retrieved from

http://kebunrayadaerah.krbogor.lipi.go.id/kebu $\underline{\text { n-raya-indrokilo-boyolali.html [Diakses pada }}$ tanggal 5 November 2019]

Peraturan Daerah Kabupaten Boyolali No. 9 Tahun 2011

Peraturan Pemerintah NO. 93 tahun 2011, tentang Kebun Botani.

Purwanti, Novi, D., \& Dewi, R. M. (2006). Pengaruh Jumlah Kunjungan Wisatawan Terhadap Pendapatan Asli Daerah Kabupaten Mojokerto. Jurnal Pendidikan Ekonomi, 3-4.

Surat Edaran menteri PUPR No. 02/SE/M/2018

Soedarso, M. N. (2014). POTENSI DAN KENDALA PENGEMBANGAN PARIWISATA BERBASIS. Jurnal Humaniora Vol 7, 136-149.

https://rimbakita.com/hutan-dataran-rendah/. Hutan Dataran Rendah - Pengertian, Ciri, Sebaran \& Manfaat. Retrieved from https://rimbakita.com/hutan-dataran-rendah/: https://rimbakita.com/hutan-dataran-rendah/ [Diakses pada tanggal 19 November 2019] 